\title{
Diversified Agglomeration, Specialized Agglomeration, and Emission Reduction Effect-A Nonlinear Test Based on Chinese City Data
}

\author{
Neng Shen ${ }^{1}$, Yuqing Zhao ${ }^{1}$ and Qunwei Wang ${ }^{2, *}$ \\ 1 College of Public Administration, Huazhong University of Science and Technology, Wuhan 430074, China; \\ 2018010019@hust.edu.cn (N.S.); 2018612029@hust.edu.cn (Y.Z.) \\ 2 College of Economics and Management, Nanjing University of Aeronautics and Astronautics, \\ Nanjing 211106, China \\ * Correspondence: wqw0305@nuaa.edu.cn; Tel.: +189-126-05407
}

Received: 23 April 2018; Accepted: 12 June 2018; Published: 13 June 2018

\begin{abstract}
Industrialization and urbanization has rapidly advanced in China. Therefore, clarifying the relationship between industrial agglomeration and environmental pollution resolves questions if intensive or dispersed development should be adopted for the future Chinese industry or not. By distinguishing between specialized and diversified agglomeration, this paper adopts the threshold regression method to investigate the differentiated influence of industrial agglomeration stages on pollution emission reduction. This was based on panel data from 2003 to 2016 on 285 prefecture-level cities in China. The result indicates that moderate degrees of industrial agglomeration and suitable agglomeration modes are conducive for the reduction of pollution emission. From a perspective of environmental protection, the development of diversified agglomeration is superior to that of specialized agglomeration. Specifically, a "U-shaped" relationship was found between specialized agglomeration and environmental pollution, suggesting that the former first mitigated and then worsened environmental pollution. This staged evolution of diversified agglomeration exerts a more-complex influence on environmental pollution. The following policy implications have been proposed: The currently implemented industrial growth pole strategy in China should fully utilize the "self-purification" effect of agglomeration to achieve energy conservation and emission reduction. Furthermore, differentiated agglomeration policies should be formulated in response to various growth poles according to different stages of industrial agglomeration. In addition, efforts should be made towards creating an interactive early warning mechanism for the spatial distribution of both economic activities and pollution.
\end{abstract}

Keywords: industrial agglomeration; threshold regression; self-purification effect; crowding effect; environmental technology spillover

\section{Introduction}

The relationship between urban agglomeration and economic growth has not only attracted attention from academic researchers, but has also become a major policy concern [1-6]. Differing from localization economies (implying that firms can derive benefits from the presence of same industry firms in a geographical area), agglomeration suggests that firms can benefit from diversified economic activities' geographical concentration in a particular area $[7,8]$. It refers to inter-industry externalities with an emphasis on city diversification across different industries and corresponds closely to the ideas by Jacob (1969), emphasizing the role of regional economies' diversity [9-11]. While localization economies have received research attention since the contributions of Marshall (1920), more contributions have been made to urban agglomeration [12-14]. The externality effects 
of specialization and diversification agglomeration are theoretically conducive to the reduction of production costs and the improvement of innovation capacity, and help further the improvement of total factor productivity [15-18]. With the gradual perfection of the market economy and the continuous strengthening of reform and opening-up in China, numerous enterprises have chosen coastal areas as locations. These companies have followed this strategy to create an agglomeration effect and reduce transaction cost, thus achieving a more-advanced market economy and raising a batch of industrial agglomeration belts (Jin, 2015) [19]. Industrial agglomeration plays an active role in enhancing industrial competitiveness, optimizing resources allocation, and encouraging technological innovation, and has become an important factor that fuels the rapid growth of the national economy (Fan et al., 2014) [20].

However, like many countries that are also experiencing an economic transition, and because of the increased resources consumption caused by the spatial agglomeration of economic activities, China suffers from air pollution, acid rain, and a series of other severe environmental problems. According to statistics of the Global Carbon Atlas, as early as 2005, China had already surpassed the United States as the world's biggest emitter of carbon dioxide (Global Carbon Atlas, 2017) [21]. Cities are regarded as carriers of economic activities, which also account for approximately $85 \%$ of China's $\mathrm{CO}_{2}$ emissions (Mi et al., 2016) [22].This suggests that agglomeration constitutes an important factor in the increase of pollution (Zheng et al., 2013; Wang et al., 2015) [23,24]. However, the emission reduction effect of industrial agglomeration may have played an intangible role (Cole et al., 2008; Otsuka et al., 2014) $[25,26]$. For example, during the process of industry transfer, no new "scattered" distribution of industries is observed, regardless of whether those are introduced or transferred outward; instead, the government now conducts large-scale pollution control by establishing unified industry parks. These not only facilitate the sharing of pollution control resources, but also increase the convenience for centralized environmental regulation by the government. The above two factors provide an ideal research opportunity, which question if industrial agglomeration has increased emitted pollution or promoted emission reduction. Considering the rapid advancement of industrialization and urbanization in China, achieving coordinated development of both economy and environment is a vital theoretical and practical issue. If industrial agglomeration makes pollution worse (under environmental and energy restraints), the scientificity of the intensive development pattern of industrial production must be re-examined; if industrial agglomeration mitigates pollution, this suggests that industrial spatial agglomeration exerts an inner emission reduction mechanism consistent with the current policy orientation of the government regarding environmental pollution control (Dengke, 2018) [27]. Apparently, clarifying the relationship between industrial agglomeration and environmental pollution not only necessitates an investigation into the environmental performance of industrial development in China for recent years, but also offers an answer to the question as to whether intensive development or dispersed development should be adopted in future or not.

\section{Literature Review}

Based on whether the externality of agglomeration originates from the same industry type, industrial agglomeration can be divided into two modes: specialized agglomeration and diversified agglomeration. One academic debate in the field of agglomeration literature is related to the question whether regional specialization within a narrow set of economic activities, or the diversity and variety of complementary competencies and activities encourage innovation and industrial growth or not. This widely studied issue, which is especially relevant in the high-technology sector, has been studied to understand the extent to which knowledge spillovers take place within and across industries. According to a theory by Marshall-Arrow-Romer, knowledge spillovers, that is, dynamic externalities, take place within industries. The Marshall-Arrow-Romer model formalizes the insight that concentration of an industry, namely, specialization in a city, facilitates knowledge spillovers between firms and therefore innovation and growth in that industry (Feldman et al., 1999) [28]. Regionally specialized industries grow faster because neighboring firms can learn from each other 
much better than geographically isolated firms. Local industry agglomeration may also increase innovation directly by providing industry-specific complementary assets and activities that may either lower the cost of supplies to the firm or create greater specialization in both input and output markets (Feldman, 1999) [29]. The findings of Feldman and Audretsch (1999) support the existence of these kinds of externalities (Beaudry, 2009; Fan, 2014; Zhu, 2017) [20,30,31].

Another view, traditionally attributed to Jacobs (1969), is that the diversity of industries within a geographic region, promotes innovative activities in firms (Glaeser et al., 1992) [32]. Externalities are external to industries but internal to geographic units such as cities. According to this view, the most important source of knowledge spillovers is external to the industry in which the firm operates and therefore cities (with many different kinds of industries) are the sources of innovation because the diversity of these sources is greatest in them (Acs, 2002) [33]. Agglomeration of industries and the network of specialized suppliers increase innovative opportunities by bringing together complementary activities and by reducing search costs. Generally speaking, the findings of empirical literature, provided by Batisse (2002) and Cheng (2014), for instance, are consistent with the presence of Jacobs-type externalities [34,35]. In some studies, externalities that arise purely from urban size and density of region (population, establishment, etc.) have been separated from Jacobs externalities stemming from a variety of sectors (Frenken et al., 2007) [36]. In addition to the above studies, some other scholars support both MAR and Jacobs externalities. Forni and Paba (2002) empirically analyzed the effects of industrial specialization and diversification on Italy's manufacturing department growth via the employment data of three-digit industries [37]. The result indicates that the industrial agglomeration effect is vital in regional industrial growth and that industrial specialization and diversification have a significant facilitating function for most manufacturing industries. Simonen (2015) pointed out that both moderate specialization and diversification play a positive role in driving regional economic growth; however, they are subject to influence by the city scale, agglomeration structure, and other conditions [38]. Yuan (2017) show that MAR externalities enhance technical efficiency by pulling up pure technical efficiency and accelerate the progress of technology. Jacobs' externalities increase scale efficiency and technical progress but decrease pure technical efficiency [39].

A more recent view of the role of agglomeration externalities is based on the concepts of related and unrelated industries (Frenken and Boschma 2007; de Groot et al., 2009) [40]. This view shares the idea of the positive effect of Jacobs-type, inter-sector spillovers. However, the difference is that, even knowledge spillovers are geographically bound and flow across industries; their effect on regional growth depends on the extent whether knowledge flows across complementary or non-complementary industries and sectors. Knowledge flows support regional development only if its industry composition is such that industries are technologically closely related (Boschma et al., 2009) [41]. A region specializing in a particular composition of complementary sectors will experience higher growth rates than a region specializing in sectors that do not complement each other (Frenken et al., 2007) [36]. According to this view, which is in line with findings provided by Boschma et al. (2012), Greunz (2003), Boschma et al. (2015), and Cainelli et al. (2016), firms and start-ups will or should agglomerate in regions where technological proximity between the firms is high [42-45]. Frenken et al. (2007) studied the role of industrial diversification more closely by analysing whether related or unrelated diversification of industries is rewarding for regional stability and growth [36]. Their results show that related diversification of industries enhances employment growth and dampens unemployment. However, they did not find effects of industry relatedness on productivity growth. In case of the Finnish data, Hartog et al. (2012) found a positive effect on regional employment growth only in a case of high-technology related variety [46].

In recent years, and with environmental pollution problems becoming gradually more prominent, industrial agglomeration, as one of the most important economic development patterns, has been receiving increasingly extensive attention with regard to its environmental externality; however, no agreement has yet been reached regarding conclusions. One conclusion is that industrial 
agglomeration will increase regional environmental pollution. Due to the agglomeration of economic activities, the expanding output scale will induce an increase of pollution emission load. Based on an empirical analysis, Virkanen (1998) suggests that the industrial agglomeration of southern Finland is an important factor that contributes to both air and water pollution in Finland [47]. Leeuw (2001) uses data of 200 cities of the EU in his analysis and concludes that a significant correlation exists between industrial agglomeration and air pollution [48]. Verhoef (2002) adopts a spatial equilibrium model and reports that industrial distribution leads to environmental pollution in agglomeration belts [49]. Duc (2007) reports that the water pollution of the Nhue River in Vietnam is mainly caused by organic carbon, phosphorus, nitrogen, and other elements of industrial waste in the region [50]. Cheng (2016) used a spatial simultaneous equations (SSE) model to analyze the interaction between manufacturing agglomeration and environmental pollution. The results indicated that manufacturing agglomeration aggravates environmental pollution, while environmental pollution restrains manufacturing agglomeration [51].

Another conclusion is that industrial agglomeration will decrease regional environmental pollution. Relying on a spillover effect of green knowledge, environmental protection resources sharing, and similar effects, industrial agglomeration can accelerate environmental innovation, increase energy utilization efficiency, and thus promote pollution emission reduction. By constructing a spatial economic growth model, Zeng and Zhao (2009) claim that industrial agglomeration will mitigate the "pollution haven" effect [52]. Enrenfeld (2003) reports that, in the process of industrial agglomeration, enterprises present a symbiotic state due to the presence of material exchange, and that based on this, they can realize the recycling of material resources and thus reduce pollution emission [53]. Wagner and Timmins (2009) suggest that the agglomeration effect of the chemical industry is an important factor that elevates the environmental threshold of foreign direct investment (FDI) inflows [54]. Yao (2017) published an empirical study using spatial econometric methods and claimed that industrial agglomeration had a significant impact on smog pollution, while industrial output agglomeration reduced it [55]. Effiong (2018) used a semi-parametric panel fixed-effects regression technique and showed that urbanization reduces environmental pollution [56].

The third view suggests that the relationship between industrial agglomeration and environmental pollution is still uncertain. The reasons are as follows: On one hand, as previously determined, industrial agglomeration can have both positive and negative effects on environmental pollution, while the overall effect depends on variable that dominates. In different stages of economic development, the relationship between industrial agglomeration and environmental pollution will vary (Zhang et al., 2015) [57]. On the other hand, many intermediate variables exist, which affect the relationship between industrial agglomeration and environmental pollution, such as size of the city, its marketization level, the degree of industrial agglomeration (He et al., 2014), industrial structure, and technological innovation (Zeng et al., 2009) [52,58].

The above studies indicate that environmental externalities of industrial agglomeration do exist; however, whether they are positive or negative is still a cause of major differences. This testifies to the complexity of the relationship between industrial agglomeration and environmental pollution. On one hand, published studies have verified the differences in the action mechanisms of different agglomeration modes on resources allocation, industrial structure, and technological innovation; however, studies on their environmental externalities have not provided more profound discussion with different agglomeration modes. On the other hand, while analyses of existing studies are mostly based on a static perspective, the development of industrial agglomeration typically manifests as a progressive and periodic evolution process, i.e., industrial clusters at different evolutionary stages have different characteristics and thus may create different environmental externalities. However, existing publications have not yet analyzed the influence of industrial agglomeration on pollution emission reduction from a perspective of the dynamic evolution of industrial agglomeration.

Due to these deficiencies of existing publications, this paper attempts to expand their boundaries by investigating the following aspects: First, theoretically referring to the Copeland-Taylor model 
(Copeland and Taylor, 1994), this paper constructs a theoretical model for the influence of industrial agglomeration on environmental pollution and takes a closer look at the relationship between industrial agglomeration and environmental pollution [59]. Second, considering that specialization and diversification constitute two different modes of industrial agglomeration and that the environmental externalities of both agglomeration modes feature different creation and action mechanisms, this paper suggests that investigating the environmental externalities of specialized and diversified agglomeration separately is particularly important. Third, the "cluster life cycle" theory suggests that clusters at different stages of their life cycle present different characteristics in terms of resource allocation efficiency, R\&D efficiency, competition degree, public facility construction, and inter-enterprise cooperation (Jirčíková et al., 2013; Mads and Torben, 2013) [60,61]; therefore, this paper takes the dynamic evolution of industrial agglomeration into perspective and employs the panel threshold model to investigate the different pollution emission reduction effects created by the transition of agglomeration development stages. Fourth, existing studies mostly select a single pollutant index; however, environmental pollution is a comprehensive effect of multiple pollutants and it is therefore difficult to reflect the overall status of environmental pollution with a single pollution index. To comprehensively reflect the overall status of environmental pollution, this paper adopts the entropy method and constructs a comprehensive index of environmental pollution. Finally, the majority of studies use provincial regions as the object of their empirical study; however, considering the vast territory of China, this approach may end up covering the true factors of industrial agglomeration. In contrast, cities enjoy many advantages in terms of infrastructure, human capital, and other relevant factors and their industrial agglomeration effect is more obvious. Therefore, adopting data on prefecture-level cities can better depict the relative contributions of industrial agglomeration to pollution emission reduction of different cities.

\section{Theoretical Model}

Based on introducing agglomeration function and referring to the Copeland and Taylor model, this paper establishes a general linear model to study the influence of industrial agglomeration on environmental quality. It further introduces the factor of the transition of agglomeration development stages and extends the linear model into a nonlinear threshold model, so as to differentiate the differences of such an influence on different agglomeration development stages.

In the existing literature, general equilibrium analysis of industrial agglomeration and environmental pollution is mostly based on the theory of Taylor and Copeland (1994). The specific method is to create an expression of enterprise emission level on the basis of the standard Copeland-Taylor model and introduce agglomeration factors into that expression to construct a theoretical model and conduct an analysis of related issues.

The basic assumption is that enterprise production needs only elements of capital and labor; the returns to scale are constant and the production function follows the Cobb-Douglas form; the product is denoted by $X$ and it discharges pollutant $Z$. When the delimitation of property rights is clear, the enterprise needs to pay corresponding $\cos t \lambda$ for its pollution emission behavior; in this regard, in general, rational enterprises would take out part of the production elements to conduct control over pollution emission. Therefore, it has been assumed that the proportion of the production elements used in pollution control is $\gamma \in[0,1]$. When $\gamma=0$, the enterprise does not conduct any pollution control. Under this condition, the enterprise's potential output is F; when $0<\gamma<1$, the enterprise conducts some pollution control, its actual output is $X=(1-\gamma) F$, and it will produce pollutants $Z=\varphi(\gamma) F$. $\varphi(\gamma)$ is a decreasing function of $\gamma$ and its expression is $\varphi(\gamma)=A^{-1} 1-\gamma^{1 / \alpha}$, where A represents the production technology, with the parameter $\alpha \in(0,1)$. By substituting $\varphi(\gamma)=A^{-1} 1-\gamma^{1 / \alpha}$ into $Z=\varphi(\gamma) F$, and $Z=A^{-1} 1-\gamma^{1 / \alpha} F$ is obtained, from which the expression of $1-\gamma$ can then be obtained. Substituting it into $X=(1-\gamma) F$ results in the following:

$$
\mathrm{X}=A Z^{\alpha}[F(K, L)]^{1-\alpha}
$$


According to the assumption above, the enterprise will face two mutually independent production decisions: one is how to choose the optimal capital-labor ratio to minimize the production cost of unit potential output $C_{F}$ when both capital cost $r$ and wage $w$ is exogenous; the other is how to choose the optimal pollution emission capacity $Z$ and potential output $F$ to minimize the production cost of unit product $C_{X}$ under the condition that the cost of pollution emission $\lambda$ and the production cost of unit potential output $C_{F}$ are given. The specific formulas can be expressed as follows:

$$
\begin{gathered}
C_{F} w, r=\min \{r K+w L, F(K, L)=1\} \\
C_{X}\left(C_{F}, \lambda\right) \min =\left\{\lambda(A Z)+C_{F} F,(A Z)^{\alpha} F^{1-\alpha}=1\right\}
\end{gathered}
$$

The optimal solutions derived from Formulas (2) and (3) are:

$$
\begin{gathered}
\operatorname{TRS}_{K L}=\frac{\partial F}{\partial K} / \frac{\partial F}{\partial L}=\frac{r}{w} \\
(1-\alpha) A Z / \alpha F=\frac{C_{F}}{\lambda}
\end{gathered}
$$

After the above-mentioned production decisions, the enterprise's pollution emission decision is then considered completed. Supposing the price of product $X$ is exogenous, denoted by $P_{X}$, the total revenue can be obtained from $T R=P_{X} X$, and the total cost can be obtained from $T C=C_{F} F+\lambda A F$. When the market is a perfectly competitive market, the following can be obtained:

$$
P_{X} X=C_{F} F+\lambda A F
$$

From Formulas (5) and (6), the following can be obtained:

$$
Z=\alpha P_{X} X / \lambda A
$$

Industrial agglomeration is to be further discussed in combination with the analysis provided in the literature review and the preceding part of this paper. At present, the existing externality theory of industrial agglomeration can be divided into two groups: The externality theory of industrial agglomeration represented by Marshall proposed the idea that industrial agglomeration carries an obvious positive economic externality, which is an important source to maintain the industry's competitiveness. With the further development of this theory, many scholars found that industrial agglomeration also carries an obvious positive environmental externality. They elaborated from the perspectives of the related technology spillover between enterprises, the scale effect of pollution control, cyclical economy, etc. in the context of collaborative innovation. These scholars consequently suggested that industrial agglomeration could achieve the effect of environmental governance. Moreover, some theories introduced the idea that industrial agglomeration can present negative externality. New economic geography suggests that industrial agglomeration can cause the phenomenon of overcrowding after reaching a certain degree; consequently, environmental pollution is one of the reflections of the above-mentioned phenomenon. Therefore, the agglomeration effect is introduced to the enterprise's production function and it is assumed that the agglomeration effect conveys both positive and negative externalities to the enterprises in a region (Wang, 2016) [62]. Under this condition, the following can be obtained:

$$
F(K, L)=\Delta(a l) f(k, l)=\exp (\sigma a l) K^{b} L^{1-b}
$$

where, al denotes the regional agglomeration effect; the agglomeration function $\Delta(a l)=\exp (\sigma a l)$ impacts the enterprise's output through both positive and negative externalities; the symbol of 
parameter $\sigma$ depends on the degree of the two externalities mentioned above. Substituting Formula (8) into Formula (7), the following formula can be derived:

$$
Z=\varepsilon \lambda^{-1} A^{-1} \exp (\sigma a l) k^{b} L^{1-b}
$$

In which $\varepsilon=\alpha(1-\gamma) P_{x}$. Both sides of Formula (9) are divided by the taken logarithm and the formula of the discharge capacity can be obtained as follows:

$$
\ln Z=\ln \varepsilon-\ln \lambda-\ln A+\sigma a l+b \ln K+(1-b) \ln L
$$

Formula (10) shows that when industrial agglomeration forms, the agglomeration effect presents both positive and negative externalities on the enterprises in a region. This means that when the positive externality of the agglomeration effect is greater than its negative externality, pollution emission is negatively correlated with the agglomeration effect and the positive externality produced by agglomeration will mitigate environmental pollution. In contrast, when the negative externality of the agglomeration effect is greater than its positive externality, the increase of the agglomeration degree will increase pollution emission.

\section{Model Specification and Variable Declaration}

\subsection{Threshold Regression Method}

To test the influence of both specialized agglomeration and diversified agglomeration at different development stages on the heterogeneity of pollution emission reduction, this paper extends the linear model into a nonlinear model. The traditional method of testing a nonlinear relationship between variables is to introduce a quadratic term of the core variable; however, this method cannot describe the staged evolution of industrial agglomeration and thus makes it impossible to analyze nonlinear characteristics of its influence on pollution emission reduction. For a nonlinear model in regression analysis, the entire sample is typically split into several subsamples for separate regression to test the stability of coefficient estimates (Chen, 2003) [63]. To distinguish between different subsamples, researchers generally have to first define the threshold value of an economic variable using their subjective judgment and then split the sample into several subsamples based on this subjective threshold value. The problem is that the results obtained in such a way are not accurate, as neither parametric regression for the threshold value nor any test on its significance can be used. Thus, according to the "threshold regression" method proposed by Hansen (1999), this paper establishes a threshold model for nonlinear regression, to endogenously split the sample into subsamples based on the intrinsic characteristics of the data, thus avoiding subjective biases [64].

The basic form of the Hansen threshold is:

$$
y_{i t}=\mu_{i}+\beta_{1} X_{i t} \cdot I\left(q_{i t} \leq \gamma\right)+\beta_{2} X_{i t} \cdot I\left(q_{i t}>\gamma\right)+\varepsilon_{i t}
$$

where the sample data can be expressed as $\left\{y_{i t}, x_{i t}, q_{i t}\right\}_{i=1, \cdots, N ; t=1, \cdots, T^{\prime}} ; i, t$ respectively represent individual and time; $y_{i t}$ represents the explained variable; $x_{i t}$ represents the explanatory variable; $q_{i t}$ represents the "threshold value" for sample splitting (also available as an explanatory variable); $\gamma$ represents the threshold value to be estimated; $\mu_{i}$ represents the unobserved characteristics of an individual; $\varepsilon_{i t} \sim$ a.i.d. $N\left(0, \delta^{2}\right)$ represents the disturbing term; $I(\cdot)$ represents the indicator function, i.e., if the expression in the brackets is true, it will be set to 1 ; otherwise, it will be set to 0 .

This is followed by the nonlinear least squares (NLS) method to estimate both the threshold value $\gamma$ and parameter $\beta$, i.e., to minimize the sum of squares for residuals. If $\gamma$ value is given, we can assume $z_{i t 1} \equiv x_{i t} \cdot I\left(q_{i t} \leq \gamma\right)$ and $z_{i t 2} \equiv x_{i t} \cdot I\left(q_{i t}>\gamma\right)$ and convert Formula (11) into a linear regression model, i.e., $y_{i t}=\mu_{i t}+\beta_{1} z_{i t 1}+\beta_{2} z_{i t 2}+\varepsilon_{i t}$; after that, we can employ the ordinary least squares (OLS) 
method to estimate $\beta_{1}(\gamma)$ and $\beta_{2}(\gamma)$, calculate the sum of squares for residuals $\operatorname{SSR}(\gamma)$, and select $\gamma$ to minimize $\operatorname{SSR}(\gamma)$. The ultimate obtained parameter estimator can be denoted by $(\beta 1(\hat{\gamma}), \beta 2(\hat{\gamma}), \hat{\gamma})$.

The threshold model test is divided into a significance test on the threshold effect and an authenticity test on threshold estimates. When it comes to testing the presence of the threshold effect, we can test the original hypothesis $H_{0}: \beta_{1}=\beta_{2}$. That is, the sum of squares for residuals obtained with this restraint is denoted by $S S R^{*}$, and the sum of squares for residuals obtained without such restraint is denoted by $\operatorname{SSR}(\hat{\gamma})$; furthermore, $\operatorname{SSR} R^{*} \geq \operatorname{SSR}(\hat{\gamma})$. This indicates that the higher the value of $\left[S S R^{*}-S S R(\hat{\gamma})\right]$, the higher the tendency of rejecting the original hypothesis. If the original hypothesis $H_{0}: \beta_{1}=\beta_{2}$ holds true, there is no such threshold effect; if it can be rejected, there is a threshold effect. The next step is to test the authenticity of the threshold value, i.e., to test $H_{0}: \gamma=\gamma_{0}$; then, the confidence interval of $\gamma$ can be calculated by conducting a likelihood ratio test on the statistics of $L R(\gamma) ; L R(\gamma)$ :

$$
\operatorname{LR}(\gamma) \equiv\left[\operatorname{SSR}(\gamma)-\operatorname{SSR}(\hat{\gamma}) / \hat{\sigma}^{2}\right], \text { where } \hat{\sigma}^{2} \equiv \frac{\operatorname{SSR}(\hat{\gamma})}{n(T-1)}
$$

The above parameter estimation and significance test are both conducted with regard to the single-threshold model. When a model uses two or more threshold values, it is necessary to extend the model; for details, please refer to the description originally provided by Hansen (1999), as we will not go into detail here.

\subsection{Model Specifications}

According to Formula (10) and in reference to the idea of Hansen's threshold model (1999), an econometric model is provided in the following threshold regression forms; i.e., in the threshold regression model for specialized agglomeration and in the model for diversified agglomeration:

$$
\begin{aligned}
& \text { Model 1: } \ln Z_{i t}=\alpha_{i}+\beta_{11} M A R_{i t} \cdot I\left(q_{i t} \geq \gamma_{1}\right)+\beta_{12} M A R_{i t} \cdot I\left(q_{i t}<\gamma_{1}\right)+\beta_{n} X+\varepsilon_{i t} \\
& \text { Model 2: } \ln Z_{i t}=\alpha_{i}+\beta_{21} J C R_{i t} \cdot I\left(q_{i t} \geq \gamma_{2}\right)+\beta_{22} J C R_{i t} \cdot I\left(q_{i t}<\gamma_{2}\right)+\beta_{n} X+\varepsilon_{i t}
\end{aligned}
$$

where $Z$ represents the pollution emission load; $M A R$ and JCR represent both specialized agglomeration and diversified agglomeration, respectively; $I(\cdot)$ is the characteristic function; $q_{i t}$ represents the threshold variable; $\gamma_{i}(i=1,2)$ represents the threshold value to be estimated; $X$ represents a group of other control variables influencing environmental pollution, mainly consisting of FDI, environmental regulation, energy consumption, and technological progress.

\subsection{Variable Selection and Data Declaration}

The data of this paper is derived from the China City Statistical Yearbook, China Statistical Yearbook for Regional Economy, and the statistical bulletins of the environment of various prefecture-level cities from 2003 to 2016. Considering the unification and completeness of the data scale and the administrative division adjustment of some prefecture-level cities, this paper ultimately adopts 285 prefecture or higher-level cities in China as sample. All monetary aggregates have been adjusted into comparable prices according to relevant price indices; 2003 is used as a base period. See the variable declaration below:

1. Pollution emission (Z): To comprehensively reflect the overall status of environmental pollution, this paper adopts the entropy method and constructs a comprehensive index of environmental pollution. It selects three main industrial pollutants, i.e., sulfur dioxide, industrial waste water, and industrial dust and measures these with their emissions per unit industrial output, respectively. 
This paper uses a dimensionless method to process the original data:

$$
p_{i j}=\frac{x i_{j}-\min x_{i j}}{\max x_{i j}-\min x_{i j}}
$$

where $x_{i j}$ represents the original value of the $j$ th industrial pollution index of the $i$ th city $(i=1,2, \ldots, 285$; $j=1,2,3)$.

On processing with the dimensionless method, the data is shifted:

$$
p^{\prime}{ }_{i j}=1+p_{i j}
$$

The proportion of the $j$ th industrial pollution index of the $i$ th city can be calculated with the following formula:

$$
\omega_{i j}=p^{\prime}{ }_{i j} / \sum p^{\prime}{ }_{i j}
$$

The entropy and coefficient of variation of the $j$ th industrial pollution index can be calculated with the following formula, where $m$ equals 285 :

$$
\pi_{j}=-\frac{1}{\ln m} \sum \omega_{i j} \ln \omega_{i j}, g_{j}=1-\pi_{j}
$$

The weight of the $j$ th industrial pollution index in the comprehensive evaluation can be calculated with the following formula:

$$
W_{j}=g_{j} / \sum g_{j}
$$

By simultaneously solving Formulas (15)-(18), we can obtain a comprehensive index of industrial pollution:

$$
Z_{i}=\sum W_{j} \omega_{i j}
$$

where $Z_{i}$ represents the comprehensive index of industrial pollution of the $i$ th city; i.e., the higher the value, the higher the degree of industrial pollution. Considering that China's industries are mainly distributed in municipalities that are directly under the central government, provincial capitals, and municipalities with independent planning status, and that the scope of this paper is limited, Table 1 only lists the comprehensive indices of industrial pollution of a subset of Chinese cities during 2003-2016.

As can be preliminarily seen from the calculation results, first, during the investigation period, the industrial pollution of eastern cities was noticeably more severe than that of central and western cities, and the industrial pollution of municipalities directly under the central government, provincial capitals, and municipalities with independent planning status was more severe than that of prefecture-level cities. This basically matches the spatial layout of China's industries during recent years. Second, the overall industrial pollution of Chinese cities presented a trend of continuous deterioration, as manifested in the constant increase of the comprehensive industrial pollution index of the same city. To be specific, the industrial pollution deterioration rate of eastern cities was noticeably higher than that of both central and western cities.

In 2008, the Worldwide Fund for Nature (WWF) specified Shanghai and Baoding as experimental units and launched the "low-carbon city" development demonstration project. In 2010, the government of China (GOC) announced the low-carbon pilot work in the first five provinces and eight cities, including the five provinces of Guangdong, Liaoning, Hubei, Shaanxi, and Yunnan and the eight cities of Tianjin, Chongqing, Shenzhen, Xiamen, Hangzhou, Nanchang, Guiyang, and Baoding. In 2012, the National Development and Reform Commission (NDRC) announced the directory of the low-carbon experimental units in a second group of 29 provinces and cities, including Beijing, Shanghai, Shijiazhuang, Suzhou, Wuhan, Guangzhou, Kunming, Urumchi, etc. The two groups of low-carbon experimental units include 42 provinces and cities in total, the population of which accounts for about $40 \%$ of the Chinese population 
and the GDP accounts for about $60 \%$ of the total GDP of China. Low-carbon experimental units have basically been expanded nationwide. According to the requirements of low-carbon experimental work for provinces and cities, the experimental cities conducted the following work: formulating and perfecting green development planning, exploring and establishing a green development mechanism, strengthening the adjustment of industrial structure to initialize an eco-friendly industrial system, establishing green assessment and evaluation mechanisms, and establishing the concept of green consumption and green life. All experimental cities conducted a series of experimental explorations in combination with their own characteristics. For example, Baoding proposed the concept of the "Electricity Valley of China", and created seven large industrial parks for photovoltaic power system, wind power, electric transmission and transformation equipment, new-type energy storage, energy efficiency, power electronic devices, electric power automation, and power software, thus effectively promoting the integration of industrial development and low-carbon cities. Suzhou implemented industrial pollution control in the Taihu Lake Basin, positively promoting and standardizing the development of the technology-based tertiary industry. Furthermore, Suzhou conducted energy-saving audits on key units, using energy to explore their energy-saving potential.

Table 1. The comprehensive index of industrial pollution of provincial capitals and municipalities in China (2002-2016) (Unit: 10-4).

\begin{tabular}{|c|c|c|c|c|c|c|c|c|c|c|c|c|c|c|}
\hline City & 2003 & 2004 & 2005 & 2006 & 2007 & 2008 & 2009 & 2010 & 2011 & 2012 & 2013 & 2014 & 2015 & 2016 \\
\hline \multicolumn{15}{|l|}{ Eastern } \\
\hline Beijing & 3.514 & 3.530 & 3.530 & 3.527 & 3.527 & 3.552 & 3.624 & 4.052 & 3.634 & 3.765 & 3.805 & 3.654 & 3.604 & 3.712 \\
\hline Tianjing & 3.460 & 3.454 & 3.474 & 3.452 & 3.549 & 3.537 & 3.525 & 3.642 & 3.625 & 3.634 & 3.711 & 3.745 & 3.698 & 3.701 \\
\hline Shijiazhuang & 3.550 & 3.546 & 3.607 & 3.527 & 3.515 & 3.494 & 3.543 & 3.569 & 3.587 & 3.656 & 3.698 & 3.723 & 3.775 & 3.680 \\
\hline Shanghai & 3.462 & 3.456 & 3.497 & 3.586 & 3.451 & 3.434 & 3.526 & 3.438 & 3.424 & 3.534 & 3.554 & 3.512 & 3.576 & 3.587 \\
\hline Nanjing & 3.460 & 3.470 & 3.456 & 3.450 & 3.544 & 3.593 & 3.526 & 3.540 & 3.627 & 3.612 & 3.646 & 3.668 & 3.704 & 3.721 \\
\hline Hangzhou & 3.494 & 3.457 & 3.464 & 3.485 & 3.547 & 3.590 & 3.530 & 3.573 & 3.626 & 3.676 & 3.878 & 3.770 & 3.786 & 3.801 \\
\hline Fuzhou & 3.443 & 3.444 & 3.466 & 3.451 & 3.435 & 3.510 & 3.626 & 3.480 & 3.495 & 3.454 & 3.502 & 3.487 & 3.465 & 3.477 \\
\hline Jinan & 3.444 & 3.445 & 3.460 & 3.438 & 3.477 & 3.484 & 3.485 & 3.490 & 3.491 & 3.521 & 3.765 & 3.832 & 3.778 & 3.732 \\
\hline Guangzhou & 3.436 & 3.437 & 3.452 & 3.463 & 3.455 & 3.485 & 3.485 & 3.461 & 3.465 & 3.468 & 3.487 & 3.478 & 3.460 & 3.475 \\
\hline Haikou & 3.425 & 3.426 & 3.424 & 3.425 & 3.429 & 3.425 & 3.423 & 3.452 & 3.464 & 3.443 & 3.455 & 3.436 & 3.455 & 3.467 \\
\hline Xiamen & 3.442 & 3.406 & 3.413 & 3.414 & 3.414 & 3.418 & 3.434 & 3.452 & 3.457 & 3.423 & 3.412 & 3.445 & 3.466 & 3.454 \\
\hline Shenzhen & 3.417 & 3.428 & 3.457 & 3.456 & 3.467 & 3.476 & 3.484 & 3.440 & 3.525 & 3.576 & 3.609 & 3.654 & 3.723 & 3.698 \\
\hline Ningbo & 3.460 & 3.470 & 3.479 & 3.494 & 3.492 & 3.510 & 3.527 & 3.547 & 3.542 & 3.676 & 3.687 & 3.667 & 3.688 & 3.701 \\
\hline Qingdao & 3.460 & 3.467 & 3.481 & 3.484 & 3.485 & 3.494 & 3.507 & 3.519 & 3.528 & 3.523 & 3.512 & 3.498 & 3.489 & 3.523 \\
\hline \multicolumn{15}{|l|}{ middle } \\
\hline Hefei & 3.445 & 3.444 & 3.443 & 3.438 & 3.480 & 3.463 & 3.476 & 3.572 & 3.528 & 3.565 & 3.623 & 3.674 & 3.711 & 3.689 \\
\hline Nanchang & 3.459 & 3.458 & 3.463 & 3.464 & 3.443 & 3.485 & 3.488 & 3.637 & 3.627 & 3.703 & 3.843 & 3.777 & 3.812 & 3.798 \\
\hline Zhenzhou & 3.420 & 3.436 & 3.439 & 3.443 & 3.437 & 3.450 & 3.453 & 3.496 & 3.498 & 3.502 & 3.487 & 3.512 & 3.633 & 3.611 \\
\hline Wuhan & 3.433 & 3.449 & 3.457 & 3.451 & 3.444 & 3.456 & 3.457 & 3.451 & 3.467 & 3.476 & 3.465 & 3.502 & 3.476 & 3.489 \\
\hline Changsha & 3.423 & 3.437 & 3.437 & 3.459 & 3.468 & 3.450 & 3.460 & 3.457 & 3.466 & 3.457 & 3.465 & 3.487 & 3.521 & 3.499 \\
\hline \multicolumn{15}{|l|}{ western } \\
\hline Nanning & 3.402 & 3.402 & 3.420 & 3.425 & 3.472 & 3.435 & 3.444 & 3.498 & 3.507 & 3.487 & 3.445 & 3.465 & 3.460 & 3.453 \\
\hline Chongqing & 3.412 & 3.413 & 3.460 & 3.455 & 3.428 & 3.466 & 3.466 & 3.424 & 3.433 & 3.456 & 3.445 & 3.458 & 3.487 & 3.490 \\
\hline Chengdu & 3.507 & 3.513 & 3.523 & 3.486 & 3.452 & 3.469 & 3.424 & 3.468 & 3.466 & 3.509 & 3.521 & 3.565 & 3.556 & 3.590 \\
\hline Guiyang & 3.418 & 3.436 & 3.474 & 3.467 & 3.472 & 3.449 & 3.424 & 3.455 & 3.465 & 3.443 & 3.487 & 3.523 & 3.532 & 3.509 \\
\hline Kunming & 3.440 & 3.439 & 3.449 & 3.440 & 3.445 & 3.426 & 3.425 & 3.442 & 3.425 & 3.421 & 3.454 & 3.434 & 3.427 & 3.443 \\
\hline Xian & 3.412 & 3.414 & 3.422 & 3.428 & 3.422 & 3.429 & 3.435 & 3.434 & 3.426 & 3.423 & 3.434 & 3.467 & 3.504 & 3.532 \\
\hline Lanzhou & 3.427 & 3.430 & 3.434 & 3.442 & 3.442 & 3.441 & 3.445 & 3.441 & 3.457 & 3.476 & 3.565 & 3.553 & 3.490 & 3.521 \\
\hline Xining & 3.401 & 3.406 & 3.428 & 3.435 & 3.432 & 3.432 & 3.446 & 3.456 & 3.452 & 3.456 & 3.476 & 3.450 & 3.456 & 3.476 \\
\hline Yinchuan & 3.400 & 3.418 & 3.416 & 3.414 & 3.420 & 3.431 & 3.446 & 3.457 & 3.486 & 3.432 & 3.443 & 3.457 & 3.508 & 3.512 \\
\hline Wulumiqi & 3.463 & 3.466 & 3.506 & 3.459 & 3.464 & 3.446 & 3.444 & 3.444 & 3.464 & 3.444 & 3.465 & 3.454 & 3.456 & 3.465 \\
\hline Huhehaote & 3.493 & 3.488 & 3.523 & 3.466 & 3.456 & 3.449 & 3.428 & 3.448 & 3.458 & 3.465 & 3.454 & 3.498 & 3.477 & 3.478 \\
\hline \multicolumn{15}{|l|}{ Northeast } \\
\hline Shenyang & & & 3.591 & 3.468 & & 3.462 & 3.465 & 3.471 & 3.526 & 3.656 & 3.876 & 3.890 & 3.901 & 4.003 \\
\hline Changchun & 3.456 & 3.437 & 3.478 & 3.455 & 3.458 & 3.437 & 3.426 & 3.447 & 3.426 & 3.498 & 3.554 & 3.598 & 3.612 & 3.598 \\
\hline Haerbing & 3.463 & 3.451 & 3.511 & 3.459 & 3.457 & 3.433 & 3.424 & 3.459 & 3.427 & 3.434 & 3.446 & 3.501 & 3.512 & 3.498 \\
\hline Dalian & 3.493 & 3.490 & 3.511 & 3.563 & 3.558 & 3.538 & 3.537 & 3.544 & 3.547 & 3.534 & 3.521 & 3.509 & 3.522 & 3.512 \\
\hline
\end{tabular}


2. Agglomeration level: For convenience of measurement, this paper divides industrial agglomeration into specialized and diversified agglomeration. In published studies, location quotient (LQ) index, revealed comparative advantage (RCA) index, and Krugman specialization index (KSI) index are typically used to measure both the regional distribution and regional specialization level of industries. This paper adopts the KSI index to measure the specialization level of cities, i.e.,

$$
M A R_{r}=\sum_{i=1}^{I}\left|\frac{L_{i, r}}{L_{r}}-\frac{L_{i}}{L}\right|
$$

where $r$ represents the city; $i$ represents the industry; $L$ represents the employment figure. $M A R_{r}$ has a range of $0-2$ and, the higher the index, the more prominent the specialization level of a city will be; $M A R_{r}=0$ indicates that the industrial structure of city $r$ is completely consistent with the industrial structure of the country.

The reciprocal of the Herfindahl-Hirschman Index (HHI) is frequently used to measure the diversification level. The diversification index at the city level can be expressed as:

$$
J A C_{r}=1 / \sum_{i=1}^{I}\left(L_{i, r} / L_{r}\right)^{2}
$$

The letters in Formula (22) have the same meaning as those in $M A R_{r}$. A higher diversification index (i.e., a lower HHI) suggests that the industrial development of the city is relatively scattered and has a significant diversification characteristic.

3. Control variables: Technological progress (TECH) - measured by the proportion of R\&D input in GDP. Technological progress follows a close relationship with environmental pollution and can increase both the energy utilization and production efficiency of an enterprise and promote its emission reduction; however, technological progress may also worsen environmental pollution due to an expansion of production scale. Industrial structure (CONS)—measured by the proportion of the added value of the secondary industry in GDP. The industrial structure determines the types and degrees of pollutants, and industries constitute a major pollution-causing industrial category; the higher the proportion of industries, the more severe the pollution will be. Foreign direct investment (FDI) - measured by the proportion of the amount of FDI actually utilized in GDP and valuated in RMB via conversion according to the central parity rates of the respective years. FDI influences the environmental quality of the host country mainly via the scale effect, the structural effect, and the technological progress effect. Environmental regulation (ER): Published studies have suggested that the increase of the inputs by the government in environmental control and protection necessarily increases the emission cost for enterprises, which prompts enterprises to conduct green technological innovation and thus helps to reduce pollution emission. The environmental regulation of a region is measured by its total investment in industrial pollution control. Energy intensity (EI): Energy consumption (e.g., coal consumption) is the direct cause of $\mathrm{SO}_{2}$ emission and the emission of other pollutants. Due to the unavailability of data regarding the energy consumption of prefecture-level cities, this paper adopts a ratio between annual industrial power consumption and regional GDP as a proxy variable of energy intensity. The economic development level is measured by per capita GDP (pGDP). Pollution emission is closely related to the stages of economic development. When the level of economic development is relatively low, pursuing the goal of economic growth results in more pollution emission; when the economic development level is relatively high, residents have higher requirements regarding environmental quality, pollution control funds are more sufficient, and environmental quality can be improved to some extent. The result of the descriptive statistics of the variables is shown in Table 2. 
Table 2. Result of the descriptive statistics of variables.

\begin{tabular}{ccccc}
\hline Variable & The Mean & The Maximum & The Minimum & The Standard Deviation \\
\hline Ln(TECH) & -3.3943 & -2.2576 & -4.1209 & -4.1264 \\
Ln(pGDP) & 10.3543 & 12.1876 & 7.9832 & 9.8987 \\
Ln(FDI) & -3.5245 & -2.8145 & -4.4740 & -3.9086 \\
Ln(ER) & 16.2165 & 17.0876 & 13.8861 & 13.1983 \\
Ln(EI) & -3.4624 & -2.5487 & -4.6968 & -4.1576 \\
Ln(CONS) & 3.8875 & 2.7546 & 4.5209 & 2.4456 \\
Ln(MAR) & -6.8654 & 0.3365 & -1.9451 & -1.5987 \\
Ln(JAC) & 1.2879 & 2.3687 & -2.3411 & 0.7713 \\
\hline
\end{tabular}

\section{Panel Threshold Regression and Result Analysis}

\subsection{Testing the Threshold Effect}

According to the principles of the threshold regression model, the threshold variable can either be an explanatory variable of the model, or any other independent variable. Menzel and Fornahl (2009) pointed out that both the evolution and development of industrial agglomeration can be measured in two dimensions: "quantity" and "quality". To be specific, "quantity" refers to the enterprise quantity and employment figure in a cluster [65]; "quality" refers to the diversification of knowledge and technology in a cluster. With regard to the difficulty in measuring the dimension of "quality", this paper uses the dimension of "quantity" to select an index with which to measure the transition of agglomeration development stages. According to the theory of spatial economics, new enterprises choose to be located in cities to create the effect of agglomeration economies; consequently, with a continuous increase of the number of enterprises, cities develop on an increasingly larger scale. Thus, industrial agglomeration is the main driver behind the emergence and development of cities and determines the scale of cities ( $\mathrm{Au}, 2006)$ [66]. Therefore, this paper uses city scale as an external manifestation of the evolution of stages of industrial agglomeration development, and thus adopts the urban population as a threshold variable. Following that, it conducts a significance test on single-threshold, double-threshold, and three-threshold models; see results in Table 3.

Table 3. Threshold effect and test result.

\begin{tabular}{ccccc}
\hline & \multicolumn{2}{c}{ Model 1 } & \multicolumn{2}{c}{ Model 2 } \\
\hline Test of Threshold & LR Testing Statistic & Threshold Value & LR Testing Statistic & Threshold Value \\
\hline single-threshold & 97.4543 & $5.5454^{* * *}$ & 105.4401 & $5.0120^{* * *}$ \\
double-threshold & 34.0494 & 5.7576 & 54.7656 & $5.5983^{* * *}$ \\
three-threshold & 14.1933 & 6.4129 & 33.9842 & $5.9073^{* *}$ \\
\hline
\end{tabular}

Note: ${ }^{*}, * * * *$ represent significance levels of $10 \%, 5 \%$, and $1 \%$, respectively.

As shown in Table 3, Model 1 passed the single-threshold test, and city scale had only one threshold value, i.e., 5.5454; the samples were endogenously classified into two groups. Model 2 passed the three-threshold test and city scale had three threshold values, i.e., 5.0120, 5.5983, and 5.9073; the samples could be classified into four groups.

\subsection{Results of the Panel Threshold Regression}

Table 4 reports the regression results of the panel threshold model. In Model 1, a "U-shaped" relationship was found between specialized agglomeration and environmental pollution, suggesting that the former first mitigated and then worsened environmental pollution. Some studies have also pointed out that the impact of agglomeration on environmental pollution is not simply linear, but has obvious non-linear characteristics (Qin and Wu, 2015; Xu and Lin, 2015) [67,68]. He and Wang (2012) believed that manufacturing agglomeration affects environmental pollution not only through 
agglomeration effects but also through congestion outcomes [69]. Vernon (2003) found that there is an optimal level of urbanization or urban concentration, in terms of maximizing environmental productivity growth [70]. However, due to the differences in agglomeration definition and index selection, the trend of $\mathrm{u}$-shaped curve shows different characteristics.

Table 4. Result of the threshold regression model.

\begin{tabular}{|c|c|c|c|c|c|}
\hline Variable & Model 1 & Variable & Model 2 & Variable & Two-Step GMM \\
\hline $\ln M A R(\ln c p \leq 5.5454)$ & $\begin{array}{c}-0.1127 * * * \\
(-4.65)\end{array}$ & $\ln J A C(\ln c p \leq 5.0120)$ & $\begin{array}{l}-1.1660 * * * \\
(-3.67)\end{array}$ & $\ln M A R$ & $\begin{array}{l}-0.1832 \\
(-0.12)\end{array}$ \\
\hline $\ln M A R(\ln c p \geq 5.5454)$ & $\begin{array}{c}0.0537 * * * \\
(3.98)\end{array}$ & $\ln J A C(5.0120<\operatorname{Ln} c p \leq 5.5983)$ & $\begin{array}{c}-0.1432 * * * \\
(-4.03)\end{array}$ & $\ln J A C$ & $\begin{array}{l}-0.0983^{* * *} \\
(-3.77)\end{array}$ \\
\hline $\ln$ cons & $\begin{array}{c}0.2012 * * * \\
(5.01)\end{array}$ & $\ln J A C(5.5983<\operatorname{Ln} c p \leq 5.9037)$ & $\begin{array}{c}-0.5456 \text { *** } \\
(-3.87)\end{array}$ & $\ln$ cons & $\begin{array}{c}0.1723 * * * \\
(4.67)\end{array}$ \\
\hline $\ln t e c h$ & $\begin{array}{l}-0.1432 \\
(-0.23)\end{array}$ & $\ln J A C(\operatorname{Ln} c p>5.9037)$ & $\begin{array}{c}0.0676^{* * *} \\
(5.21)\end{array}$ & $\ln t e c h$ & $\begin{array}{l}0.1231 \\
(0.21)\end{array}$ \\
\hline $\ln f d i$ & $\begin{array}{l}-0.0786 * * * \\
(-4.45)\end{array}$ & $\ln$ cons & $\begin{array}{l}0.1654^{* * *} \\
(4.24)\end{array}$ & $\ln f d i$ & $\begin{array}{l}-0.0545 * * * \\
(-3.65)\end{array}$ \\
\hline $\ln e r$ & $\begin{array}{c}0.0453 \text { ** } \\
(2.17)\end{array}$ & $\ln$ tech & $\begin{array}{l}-0.1129 \\
(-0.04)\end{array}$ & $\ln e r$ & $\begin{array}{l}0.2754^{* * *} \\
(3.80)\end{array}$ \\
\hline $\ln g d p$ & $\begin{array}{l}0.1832 * * * \\
(4.56)\end{array}$ & $\ln f d i$ & $\begin{array}{c}-0.0575 * * * \\
(-3.99)\end{array}$ & $\ln g d p$ & $\begin{array}{c}0.0876 * * * \\
(4.21)\end{array}$ \\
\hline $\ln e i$ & $\begin{array}{l}0.2760 * * * \\
(5.54)\end{array}$ & $\ln e r$ & $\begin{array}{c}0.0398^{* *} \\
(4.09)\end{array}$ & $\ln e i$ & $\begin{array}{c}0.1983 * * * \\
(4.43)\end{array}$ \\
\hline cons $\tan t$ & $\begin{array}{c}-0.1832 * * * \\
(-3.87)\end{array}$ & $\ln g d p$ & $\begin{array}{c}0.1553 * * * \\
(4.87)\end{array}$ & cons $\tan t$ & $\begin{array}{c}-0.0934 * * * \\
(-4.65)\end{array}$ \\
\hline \multirow[t]{3}{*}{$\mathrm{R}^{2}$} & 0.8201 & $\ln e i$ & $\begin{array}{c}0.2343 * * * \\
(3.88)\end{array}$ & $\mathrm{R}^{2}$ & 0.7898 \\
\hline & & cons $\tan t$ & $\begin{array}{l}-0.1654^{* * *} \\
(-4.21)\end{array}$ & & \\
\hline & & $\mathrm{R}^{2}$ & 0.8056 & & \\
\hline
\end{tabular}

Note: ${ }^{*}, * * * * *$ represent significance levels of $10 \%, 5 \%$, and $1 \%$, respectively; the square brackets are $t$ statistics.

A turning point occurred when the urban population reached 2,560,569 persons (Incitypop $=5.5454$, citypop $=\mathrm{e}^{5.5454}=2,560,569$ persons, the same below). When the urban population remained below $2,560,569$ persons, specialized agglomeration still remained at the stage of initial formation or growth, which was conducive for the reduction of pollution emission, with an influencing coefficient of -0.1127 ; when the urban population exceeded the threshold value of 2,560,569 persons, specialized agglomeration continuously expanded and evolved until the stage of maturation or recession was reached, in which case the influence coefficient on environmental pollution changed to 0.0537 . The results indicated that with the continuous expansion of the agglomeration scale, the congestion effect of specialized agglomeration exceeded the agglomeration effect and pollution emission increased. The classification of specific cities of China according to the threshold value is shown in Table 5.

Table 5. The classification of cities whose urban population is beyond the threshold.

\begin{tabular}{|c|c|c|}
\hline Urban Pop & Region & List of the Cities \\
\hline \multirow{4}{*}{$p \geq 256,056,9$} & eastern & $\begin{array}{l}\text { Beijing }{ }^{\mathrm{M}} \text {, Shanghai }{ }^{\mathrm{M}} \text {, Guangzhou }{ }^{\mathrm{C}} \text {, Shenzhen, Tianjin }{ }^{\mathrm{M}} \text {, Dongguan, Nanjing }{ }^{\mathrm{C}} \text {, } \\
\text { Hangzhou }{ }^{\mathrm{C}} \text {, Qingdao, Jinan }{ }^{\mathrm{C}} \text {, Xiamen, Suzhou, Ningbo, Shantou, Shijiazhuang }{ }^{\mathrm{C}}\end{array}$ \\
\hline & middle & Wuhan ${ }^{C}$, Zhenzhou $^{C}$, Hefei $^{C}$, Taiyuan ${ }^{C}$, Changsha ${ }^{C}$, Nanchang ${ }^{C}$ \\
\hline & western & Chengdu $^{C}$, Xian ${ }^{C}$, Kunming ${ }^{C}$, Nanning ${ }^{C}$, Wulumuqi ${ }^{C}$, Guiyang ${ }^{C}$, Chongqing ${ }^{M}$ \\
\hline & northeast & Shenyang ${ }^{\mathrm{C}}$, Haerbin ${ }^{\mathrm{C}}$, Changchun ${ }^{\mathrm{C}}$, Dalian \\
\hline
\end{tabular}

This is because, first, during the development process of specialized agglomeration from formation through growth to maturation, resources allocation is continuously optimized in a cluster; the knowledge and technology spillover resulting from manufacturing agglomerations can promote technological progress. This may stimulate enterprises in agglomeration regions to adopt more advanced, environmentally friendly production technologies, which can effectively reduce pollutant emissions (Baomin et al., 2012; Pessoa, 2014; Galliano et al., 2015) [71-73]. Second, the production 
activities of the same industry within a specialized cluster typically generate the same or similar pollutants; therefore, public pollution control facilities can realize specialized operations and create a scale effect (Berliant, 2013; Costantini, 2014) [74,75]. Third, the scale effect of manufacturing agglomeration can increase residential income and fiscal revenue through improved regional labor productivity. Residents in manufacturing agglomeration regions may have more strict environmental requirements in their local areas, thereby forcing the government to adopt more stringent environmental regulations and invest more in environmental pollution control (Jie, 2006, Han, 2018) [76,77]. In this case, the agglomeration effect of specialized agglomeration plays a dominant role and enhances its positive environmental externalities.

However, the resources-bearing capacity of a cluster is not infinitely expandable. When agglomeration reaches such a scale where the enterprise quantity within the cluster tends to be saturated; further expansion will result in a shortage of resources supply within the cluster, in which case the "congestion effect" will begin to seize a dominant role (Peng, 2017) [78]. In this case, the scale of the cluster is approximate to its extreme value and the constantly expanded production scale inevitably causes further pollution. When public pollution control facilities gradually become scarce resources, and induce excessive competition among enterprises, these enterprises will have to bear an increasingly increasing pollution control cost, which will further increase the behavior of "emission without a permit" or "emission beyond the limit allowed by the permit". To survive, enterprises are more likely to increase their input in product innovation; however, low-carbon innovation activities are extremely likely to be ceased due to a shortage of funds. Thus, the positive environmental externalities of specialized agglomeration will gradually be counterbalanced by their negative environmental externalities (Xu and Lin, 2015) [79]. Lastly, it is difficult to induce the knowledge and technology spillover effects because in many cases, Chinese manufacturing agglomeration is guided and promoted by the government, and not by the market. The intense and low-level homogeneous competition of similar manufacturing enterprises in the same area leads to redundant construction, blind investment, and energy waste (Cheng, 2016) [51]. These manifest as a transition of their influence on environmental pollution from a mitigation effect into deterioration.

The staged characteristics of the evolution of diversified agglomeration exert a more complex influence on environmental pollution. As indicated by the results of Model 2, the estimation coefficients of the diversified agglomeration index for the four groups of subsamples differed significantly. When citypop $\leq 1,502,048$ persons, both diversified agglomeration and environmental pollution had a negative correlation, with an influencing coefficient of -1.1660 . When $1,502,048$ persons $<$ citypop $\leq 2,699,670$ persons, diversified agglomeration still exerted an inhibitory effect on environmental pollution; however, the influencing coefficient changed to -0.1432 . When the urban population exceeded the second threshold value and ranged within the interval of $(2,699,670,3,677,119)$, the inhibitory effect of diversified agglomeration for environmental pollution rebounded significantly, with an influencing coefficient of -0.5456 . When citypop $>3,677,119$ persons, the direction of the influence of diversified agglomeration on environmental pollution experienced a "sudden change"-from an inhibitory effect to a promoting effect—and the influence coefficient was 0.0676 . The classification of specific cities in China according to the threshold value is shown in Table 6.

When the city scale is relatively small and diversified agglomeration is in the initial formation stage, a relatively small production scale indicates a relatively low pollution emission level. In this case, basic pollution control facilities or environmental protection enterprises that have already settled in the cluster are sufficient to meet the demands of pollution control. The first batch of settlers in the cluster usually obtain the first-mover advantage and consequently, excess profit, making the cluster highly attractive to external manufacturers. With the continuous increase of enterprise quantity of different industries and the accelerated expansion of diversified agglomeration within the cluster, an agglomeration effect gradually emerges. At this stage, diversified agglomeration still has positive environmental externalities. The increasingly frequent inter-enterprise exchange and technical cooperation promotes knowledge spillover. Ciccone (2002) points out that the cross-industry 
knowledge spillover effect is often the main stimulant of major innovations [15]. This explains why the technological innovation efficiency of this stage increases significantly. However, the expansion of the production scale is inevitably accompanied by an increase of pollution emission load; the transformation of technological innovation achievements also has a specific time lag, which, in combination with the possible "rebound effect" of technological progress (i.e., technological progress usually expands production scale, thus indirectly driving the increase of energy consumption), results in uncertainties of energy conservation and an emission reduction effect of technological progress (Khazzoom, 1980; Lin, 2016) [80,81]. Due to the combined action of these factors, the positive influence of diversified agglomeration on emission reduction is significantly weakened during this stage.

Table 6. The classification of cities whose urban population is beyond the minimum threshold.

\begin{tabular}{|c|c|c|}
\hline Urban Pop & Region & List of the Cities \\
\hline$p \geq 3,677,119$ & $\begin{array}{l}\text { eastern } \\
\text { middle } \\
\text { western } \\
\text { northeast }\end{array}$ & $\begin{array}{l}\text { Shanghai }{ }^{M} \text {, Beijing }{ }^{M}, \text { Guangzhou }{ }^{C} \text {, Shenzhen, Tianjin }{ }^{M} \text {, Dongguan, } \\
\text { Nanjing }{ }^{C} \text {, Hangzhou }{ }^{C}, \text { Qingdao } \\
\text { Wuhan }{ }^{C}, \text { Zhenzhou }{ }^{C}, \text { Hefei }{ }^{C} \text {, Taiyuan }{ }^{C} \\
\text { Chongqing }{ }^{M} \text {, Chengdu }{ }^{C} \text {, Xian }{ }^{C} \text {, Kunming }{ }^{C} \\
\text { Shenyang }{ }^{C} \text {, Haerdin }{ }^{C}\end{array}$ \\
\hline $2,699,670 \leq p<3,677,119$ & $\begin{array}{l}\text { eastern } \\
\text { middle } \\
\text { western } \\
\text { northeast }\end{array}$ & $\begin{array}{l}\text { Jinan }{ }^{C} \text {, Xiamen, Suzhou, Ningbo, Shijiazhuang }{ }^{C} \\
\text { Changsha }{ }^{C} \text {, Nanchang }{ }^{C} \\
\text { Nanning }{ }^{C} \text {, Wulumuqi }{ }^{C} \\
\text { Changchun }{ }^{C} \text {, Dalian }\end{array}$ \\
\hline $1,502,048 \leq p<2,699,670$ & $\begin{array}{l}\text { eastern } \\
\text { middle } \\
\text { western } \\
\text { northeast }\end{array}$ & $\begin{array}{l}\text { Shantou, Wuxi, Fuzhou C, Foshan, Linyi, Wenzhou, Tangshan, Huizhou, } \\
\text { Changzhou, Handan, Zhuhai, Xuzhou, Yantan, Zibo, Nantong, Huaian, } \\
\text { Baoding, Jining, Haikou C, Shaoxing } \\
\text { Luoyang, Nanyang, Ganzhou } \\
\text { Guiyang C, Lanzhou C, Huhehaote C, Baotou, Yinchuang C, Liuzhou } \\
\text { - }\end{array}$ \\
\hline
\end{tabular}

Note: $\mathrm{M}$ represents municipalities, $\mathrm{C}$ represents provincial capitals.

With further expansion of the scale of diversified agglomeration, excess profit generated by the agglomeration effect gradually decreases, the increase of enterprise quantity slows, the agglomeration scale tends to stabilize, and pollution emission load converges within a certain range. First, after high-efficiency technological innovation and accumulation of the previous stage, the cluster now features some relatively mature and advanced technologies, including clean production and pollution control. Second, relying on long-term development, the cluster now develops its own specialized environmental protection industries, which can conduct specialized pollution control and significantly increase efficiency. Finally, a symbiotic state exists among different types of enterprises within the cluster, which creates a closed material flow and realizes waste recycling.

With gradual saturation of the cluster capacity, there will be a series of negative externalities, such as increasing labor cost, scarcity of land resources, and increase of environmental pollution (Ozawa and Phelps, 2003) [82]. Due to strong competition for limited resources, existing enterprises that have agglomerated in the cluster will try to prevent the entry and growth of novel enterprises to avoid any further expansion of the cluster scale. Such a self-blocking mechanism also prevents the entry of new technologies and new knowledge, and locks cluster structure, knowledge spillover, and technological innovation on established paths (Martin and Sunley, 2006) [83]; as a result, the diversified agglomeration gradually moves towards recession. In such a case, the negative environmental externalities of diversified agglomeration eventually offset positive environmental externalities, resulting in the deterioration of environmental quality.

As indicated by the test results of other control variables in Model 1 and Model 2, the coefficients of industrial structure were all positive and significant at a level of $1 \%$, suggesting that industrial output results in relatively significant resources and environmental consumption. The higher the share of industries in the industrial structure, the more severe the status of environmental pollution will be (Wu et al., 2012) [84]. This is closely related to the dependence of China's urbanization of industrialization in recent years. The estimation coefficients of technological progress were negative but 
not significant, suggesting that a pollution control effect was not obvious. On one hand, this is because applications of the technological progress follow a certain time lag, which results in a relatively long cycle of emission reduction; on the other hand, this is possibly also because investment in technological progress mainly flows into fields in which a significant economic growth can be achieved instead of into the field of environmental protection. The estimation coefficients of FDI were negative and significant at the level of 1\%, suggesting that the "Pollution Haven Hypothesis" is not applicable in Chin (Wang, 2014; Pazienza, 2015) [85,86]. Foreign enterprises usually have both more advanced production and pollution treatment technologies; consequently, with regard to environmental protection standards, they tend to implement the standards of their country of origin. Furthermore, to build their image in the Chinese market, they pay closer attention to both corporate social responsibility and cooperative emission reduction, which creates a "pollution halo effect" and improves the overall environmental status of China. The influencing coefficient of environmental regulation on environmental pollution followed a significantly positive trend, suggesting that environmental regulation did not improve the status of environmental pollution in China, which is inconsistent with the theoretical expectation. To some extent, this reflects the imperfection of the existing environmental regulation system in China. In fact, the intensity of environmental regulation is generally low and, despite repeated prohibitions, an increasing number of enterprises engage in "emission without a permit" or "emission beyond the limit allowed by the permit" in various regions across the country; therefore, environmental regulation did not effectively promote pollution emission reduction (Feng, 2018) [87]. The estimation coefficients of the economic development level were negative and were all significant at the level of $1 \%$, suggesting that, with the development of the Chinese economy, the government had sufficient financial resources to conduct environmental pollution control. This furthermore suggests that the Chinese people were imposing increasingly higher requirements on environmental quality. The structure coefficient of energy consumption was significantly positive, which suggests that China's energy consumption was based on coal and other fossil fuels and that the different types of pollutants generated by the combustion of fossil fuels posed severe threats to environmental quality (Fan, 2014) [88].

Furthermore, this paper incorporates specialized agglomeration and diversified agglomeration into a unified regression model, and adopts the two-step generalized method of moments (GMM) to investigate the influence of different agglomeration modes on pollution emission. In terms of the industrial agglomeration indices addressed by this study, a negative correlation was found between specialized agglomeration and environmental pollution; however, this did not pass the significance test, meaning that specialized agglomeration did not effectively bring its emission reduction effect into play.

The reason for this is that specialized agglomeration in China can mainly be classified into two types: The first is dominated by one or several large state-owned enterprises. Due to their monopoly, they have a general lack of innovation incentives. Relying on their relatively strong market power, they can easily create a counterbalance to the government, while local governments, possibly driven by interests, may relax environmental regulations over these enterprises and indulge in pollution-related behaviors. The other type is mainly constituted of homogeneous small and medium-sized enterprises and is based on processing trade and OEM production for foreign enterprises. These enterprises are typically close to each other and can easily imitate each other; however, they lack extensive backward and forward connections. The "crowding of small and medium-sized enterprises" is not an industrial agglomeration in the real sense; in contrast, it leads to repeated construction, excess capacity, and excessive energy consumption.

A negative correlation was also found between diversified agglomeration and environmental pollution and it was significant at the significance level of $1 \%$, with an influence coefficient of -0.0983 . This suggests that diversified agglomeration offered an effective way to promote pollution emission reduction. Diversified agglomeration is better at fully allowing the competition effect and market laws to play a dominant role in resource allocation. To enhance their competitiveness, enterprises exert great efforts to reduce their energy consumption and marginal pollution control cost; furthermore, 
intense competition drives these companies to ally and cooperate with each other. As a result, the inter-enterprise spillover of environmental technology becomes more significant, greatly increasing the efficiency of environmental innovation, and effectively lowering innovation risks.

\section{Conclusions}

Referring to the Copeland-Taylor model, this paper deduces a theoretical model to investigate the influencing mechanism of industrial agglomeration on environmental pollution. Based on this model, this paper introduces panel data of 285 prefecture-level cities in China during 2003-2016, distinguishes between specialized and diversified agglomeration, and adopts the threshold regression method to investigate the differentiated influence of the transition of agglomeration development stages on pollution emission reduction from the perspective of a dynamic evolution of industrial agglomeration.

The study finds the following: First, there was a "U-shaped" relationship between specialized agglomeration and environmental pollution. When specialized agglomeration was at the stage of formation or growth, it was conducive to pollution emission reduction. When specialized agglomeration further evolved and expanded and when the congestion effect outweighed the agglomeration effect, positive environmental externalities of specialized agglomeration were gradually offset by negative environmental externalities. Second, the staged evolution of diversified agglomeration exerts a more complex influence on environmental pollution. During the initial formation of the agglomeration, a relatively small production scale indicates relatively low pollution emission levels. Then, the accelerated expansion of agglomeration scale results in a significant increase of the pollution emission load. Combined with the possible "rebound effect" of technological progress and despite its positive environmental externalities, its emission reduction effect is significantly weakened. While the agglomeration scale tends toward stabilization and under the combined action of mature technology, specialized environmental protection industries, and diversified inter-industry material circulation system, the inhibitory effect of diversified agglomeration for pollution is furthermore introduced. Finally, when the capacity of a cluster gradually saturates, outdated technology and rigid structures will lock agglomeration onto established development paths, and the recession of diversified agglomeration will induce the deterioration of environmental quality. Third, in summary, the role of specialized agglomeration in mitigating environmental pollution is not significant in China, and the "crowding of small and medium-sized enterprises" is not an industrial agglomeration in the real sense. In contrast, this leads to repeated construction, excess capacity, and excessive energy consumption; diversified agglomeration accelerates both the inter-industry and inter-enterprise spillover of environmental technology, increases the efficiency of environmental innovation and thus, promotes pollution emission reduction. From a perspective of environmental protection, the development mode of diversified agglomeration is superior to that of specialized agglomeration.

The implications of this paper are as follows: No contradiction exists between energetically increasing the density of the urban economy and promoting the spatial concentration of economic activities on one hand, while effectively protecting ecological environment on the other hand. In contrast, moderate spatial agglomeration degrees and suitable agglomeration modes of economic activities are conducive for the reduction of pollution emission. The industrial growth pole strategy currently implemented in China should follow the concept of green development, and differentiated agglomeration policies should be formulated with regard to various growth poles according to different stages of industrial agglomeration; consequently, this will lead to a full utilization of the "self-purification" effect of specialized agglomeration and diversified agglomeration for energy conservation and emission reduction and realize a harmonious unification between industrial scale growth and environmental protection. Furthermore, it is worth noting that bilateral interactions exist between the emission reduction effect and city scale evolution, with staged characteristics, and that efforts should be made towards creating a dynamic correlation monitoring system for both urban economic density and pollution data; defining economic density and pollution thresholds; creating an 
interactive early warning mechanism for the spatial distribution of both economic activities and pollution; fully utilizing the emission reduction effect of industrial agglomeration; and mitigating the pollution caused by the agglomeration of economic activities through industrial structure upgrading, environmental regulation intensification, continuous opening-up, and technological innovation.

During the development of new industrialization in China, the relationships between agglomeration, efficiency, and environment should be weighed and balanced. Industrial agglomeration is not contradictory to environmental pollution. Rational agglomeration degrees and agglomeration modes are favorable for popularization and the application of new technology, highly efficient resource utilization, and the cooperative governance of pollution. In contrast, if enterprises are relocated blindly to economically less-developed regions to force enterprises to develop in a decentralized manner, this will lower agglomeration efficiency and consequently increase environmental costs. This means that the existing household registration policy imposes restrictions on migration to large cities. The construction land index distribution policy, which is inclined to the hinterland small and medium-sized cities and towns, distorts the industrial space layout. Moreover, both are unfavorable to the realization of the goal of energy conservation and emission reduction. Based on this understanding, the following policy suggestions are provided:

Firstly, the industrial space layout should be optimized under the guidance of the idea of green development. The existing official promotion tournament system focuses excessive attention on GDP growth, which prompts government officials to only emphasize the number of enterprises and the scales of enterprises in the area under their jurisdiction, not considering whether the industry conforms to comparative advantages and industrial layout of the area. This situation leads to enterprise agglomeration, excess production capacity, and over-consumption of energy. Under the premise of establishing a dynamic monitoring and early warning system of economic density and pollution emission, a policy of integrating points and spheres should be adopted. The aim will be to continue to promote the development of small towns, while trying to promote the trans-regional reconfiguration of production factors as well as promoting the agglomeration of resources in coastal areas and regional central cities. Regional industrial space structures with reasonable layout, close link, and coordinated development will then be formed to fully achieve the energy conservation and emission reduction effects of agglomeration.

Secondly, a dynamic method should be adopted to handle the relationship between industrial agglomeration and environmental pollution. According to agglomeration degrees and characteristics of the stage of industrial development, differentiated policies of agglomeration should be adopted. Small cities lie at the left end of the U-shape curve of specialized agglomeration and environmental pollution, and have a significant specialized agglomeration pollution effect. Therefore, this should emphasize the emission reduction effect of specialized agglomeration, improve the city's specialization level, and expand both market potential and city size. Moreover, it should orientate the direction development of leading (key) industries in a region based on the local industrial base, thus encouraging the agglomeration of enterprises with the same industry in geographic locations. In addition, it should actively extend upstream and downstream of the industrial chain centering on the leading industry to increase high value-added links. Large cities lie at the right end of the U-shape curve of specialized agglomeration and environmental pollution, where the specialized agglomeration emission reduction effect is diminished; furthermore, a significant diversified agglomeration emission reduction effect appears. Therefore, mass production is not suitable for large cities. Industrial diversity should be encouraged, emphasizing the advantages of diversified agglomeration emission reduction, providing favorable diversified industrial development environment, perfecting infrastructure and effective public service, and activating the environmental technology spillover between industries and enterprises to improve green innovation efficiency.

Thirdly, industrial agglomeration transformation and upgradation is an important approach to pollution control. Industrial agglomeration follows a life cycle of its own development. When the agglomeration degree reaches a higher level, crowding, pollution, and high cost of scarce resources will 
lead to agglomeration dispersion or dying out. Under these circumstances, industrial agglomeration transformation and upgrading is essential in increasing the economic benefit and lessening the crowding effect. Industrial agglomeration transformation and upgrading can be done by raising the level of local industry and transferring the gradient space of pollution industry to improve environmental efficiency, realize the transformation of the regional economic growth mode, and fundamentally reduce the production of pollution.

Fourthly, importance should be attached to the influence conveyed by pollution industry transfer, technological advance, environmental regulation, and the policy of opening to the outside world on energy conservation and emission reduction. Industrial transfer from the east to the west is encouraged. Furthermore, corresponding conditions of industry screening and environmental-protection investigation should be defined. For industries that can cause pollution, the regions from which these industries are transferred should provide corresponding eco-compensation and environmental protection technology support for regions to which the industries are transferred. In future, China should increase investment for environmental protection and show a negative attitude toward technologies that only increase labor productivity but fail to lead to more environmentally-friendly productive processes and pollution treatment. It should also further strengthen environmental legislation and law enforcement efforts, and gradually improve environmental regulations in support of the development of the environmental protection industry. Moreover, it should further open its doors to international industries that offer a more-advanced concept of environmental protection and environmental technologies, as well as capital.

Author Contributions: N.S. and Q.W. designed the research and wrote the paper. Y.Z. analyzed the data.

Funding: This research was funded by [National Nature Science Foundation of China] grant number [71673196; 71373169].

Conflicts of Interest: The authors declare no conflict of interest.

\section{References}

1. Puga, D. Urbanization patterns: European versus less developed countries. J. Reg. Sci. 1998, 38, 231-252. [CrossRef] [PubMed]

2. Qi, J. Agglomeration and radiation effect of the pull of urbanization. Chin. Geogr. Sci. 2003, 13, 224-227. [CrossRef]

3. Finney, M.M.; Kohlhase, J.E. The effect of urbanization on labor turnover. J. Reg. Sci. 2008, 48, 311-328. [CrossRef]

4. Nakamura, R. Contributions of local agglomeration to productivity: Stochastic frontier estimations from Japanese manufacturing firm data. Pap. Reg. Sci. 2012, 91, 569-597. [CrossRef]

5. Duranton, G. Growing through cities in developing countries. World Bank Res. Obs. 2015, 30, 39-73. [CrossRef]

6. Chauvin, J.P.; Glaeser, E.; Ma, Y.; Tobio, K. What is different about urbanization in rich and poor countries? Cities in Brazil, China, India and the United States. J. Urban Econ. 2017, 98, 17-49. [CrossRef]

7. Jofre-Monseny, J.; Marín-López, R.; Viladecans-Marsal, E. The determinants of localization and urbanization economies: Evidence from the location of new firms in Spain. J. Reg. Sci. 2014, 54, 313-337. [CrossRef]

8. Glaeser, E.L.; Gottlieb, J.D. The wealth of cities: Agglomeration economies and spatial equilibrium in the United States. J. Econ. Lit. 2009, 47, 983-1028. [CrossRef]

9. Hashiguchi, Y.; Tanaka, K. Agglomeration and firm-level productivity: A Bayesian spatial approach. Pap. Reg. Sci. 2015, 94, S95-S114. [CrossRef]

10. Jacobs, J. The Economy of Cities; Random House: New York, NY, USA, 1969; ISBN-13: 978-0394705842.

11. Andersson, M.; Loof, H. Agglomeration and productivity: Evidence from firm-level data. Ann. Reg. Sci. 2011, 46, 601-620. [CrossRef]

12. Marshall, A. Principles of Economics; Macmillan and Co., Ltd.: London, UK, 1920; ISBN CNY20.00.

13. Rosenthal, S.S.; Strange, W.C. The determinants of agglomeration. J. Urban Econ. 2001, 50, 191-229. [CrossRef]

14. Melo, P.C.; Graham, D.J.; Noland, R.B. A meta-analysis of estimates of urban agglomeration economies. Reg. Sci. Urban Econ. 2009, 39, 332-342. [CrossRef] 
15. Ciccone, A. Agglomeration effects in Europe. Eur. Econ. Rev. 2002, 46, 213-227. [CrossRef]

16. Cingano, F.; Schivard, F. Identifying the sources of local productivity growth. J. Eur. Econ. Assoc. 2004, 2, 720-742. Available online: http://www.jstor.org/stable/40004879 (accessed on 8 January 2018). [CrossRef]

17. Martin, P.; Mayer, T.; Mayneris, F. Spatial concentration and plant-level productivity in France. J. Urban Econ. 2011, 69, 182-195. [CrossRef]

18. Thabet, K. Industrial structure and total factor productivity: The Tunisian manufacturing sector between 1998 and 2004. Ann. Reg. Sci. 2015, 54, 639-662. [CrossRef]

19. Jin, H.; Wentao, Y.; Xiumei, G.; Zhao, D. Creative industries agglomeration, regional innovation and productivity growth in China. Chin. Geogr. Sci. 2014, 24, 258-268.

20. Jianyong, F.; Meng, F.; Fangwen, L. Industrial agglomeration and total factor productivity of enterprises. J. World Econ. 2014, 5, 51-73.

21. Global Carbon Atlas. Available online: www.globalcarbonatlas.org/en/content/welcome-carbon-atlas (accessed on 28 March 2018).

22. Mi, Z.; Zhang, Y.; Guan, D.; Shan, Y.; Liu, Z.; Cong, R.; Yuan, X.-C.; Wei, Y.M. Consumption-based emission accounting for Chinese cities. Appl. Energy 2016, 184, 1073-1081. [CrossRef]

23. Zheng, S.; Kahn, M.E. Understanding China's Urban Pollution Dynamics. J. Econ. Lit. 2013, 51, $731-772$. [CrossRef]

24. Wang, S.; Fang, C.; Wang, Y.; Huang, Y.; Ma, H. Quantifying the relationship between urban development intensity and carbon dioxide emissions using a panel data analysis. Ecol. Indic. 2015, 49, 121-131. [CrossRef]

25. Cole, M.A.; Elliott, R.J.R.; Wu, S. Industrial activity and the environment in China: An industry-level analysis. China Econ. Rev. 2008, 19, 393-408. [CrossRef]

26. Otsuka, A.; Goto, M.; Sueyoshi, T. Energy efficiency and agglomeration economies: The case of Japanese manufacturing industries. Reg. Sci. Policy Pract. 2014, 6, 195-212. [CrossRef]

27. Chen, D.; Chen, S.; Jin, H. Industrial agglomeration and CO2 emissions: Evidence from 187 Chinese prefecture-level cities over 2005-2013. J. Clean. Prod. 2018, 172, 993-1003. [CrossRef]

28. Feldman, M.P.; Audretsch, D. Innovation in cities: Science-based diversity, specialization and localized competition. Eur. Econ. Rev. 1999, 43, 409-429. [CrossRef]

29. Feldman, M.P. The economics of innovation, spillovers and agglomeration: A review of empirical studies. Econ. Innov. New Technol. 1999, 8, 5-25. [CrossRef]

30. Beaudry, C.; Schiffauerova, A. Who's right, Marshall or Jacobs? The localization versus urbanization debate. Res. Policy 2009, 38, 318-337. [CrossRef]

31. Zhu, H.; Dai, Z.; Jiang, Z. Industrial Agglomeration Externalities, City Size, and Regional Economic Development: Empirical Research Based on Dynamic Panel Data of 283 Cities and GMM Method. Chin. Geogr. Sci. 2017, 27, 456-470. [CrossRef]

32. Glaeser, E.; Kallal, H.D.; Sheinkman, J.A.; Shleifer, A. Growth in cities. J. Political Econ. 1992, 100, $1126-1152$. Available online: http:/ / www.jstor.org/stable/2138829 (accessed on 8 January 2018). [CrossRef]

33. Acs, Z.J. Innovation and the Growth of Cities. Contrib. Econ. Anal. 2002, 266, 635-658.

34. Batisse, C. Dynamic externalities and local growth: A panel data analysis applied to Chinese provinces. China Econ. Rev. 2002, 13, 231-251. [CrossRef]

35. Cheng, Z.; Yu, B. Industrial agglomeration and regional wage gap: Spatial econometric analysis based on Chinese urban data. Mod. Econ. Sci. 2014, 36, 86-94.

36. Frenken, K.; van Oort, F.; Verburg, T. Related variety, unrelated variety and regional economic growth. Reg. Stud. 2007, 41, 685-697. [CrossRef]

37. Forni, M.; Paba, S. Spillovers and the growth of local industries. J. Ind. Econ. 2002, 50, 151-171. [CrossRef]

38. Simonen, J.; Svento, R.; Juutinen, A. Specialization and diversity as drivers of economic growth: Evidence from High-Tech industries. Pap. Reg. Sci. 2015, 94, 229-247. [CrossRef]

39. Yuan, H.; Zhang, J.; Zhang, Y.; Hong, Y.; Zhao, H. Effects of agglomeration externalities on total factor productivity: Evidence from China's Textile Industry. Ind. Text. 2017, 68, 474-480.

40. De Groot, H.L.; Poot, J.; Smit, M.J. Agglomeration, innovation and regional development: Theoretical perspectives and meta-analysis. Tinbergen Inst. Discuss. Pap. 2007, 3, 7-79. [CrossRef]

41. Boschma, R.; Frenken, K. Technological relatedness and regional branching. In Dynamic Geographies of Knowledge Creation, Diffusion, and Innovation; Bathelt, H., Feldman, M.P., Kogler, D.F., Eds.; Routledge, Taylor and Francis: London, UK, 2011; pp. 64-81, ISBN 9780415493277. 
42. Boschma, R.A.; Minondo, A.; Navarro, M. Related variety and regional growth in Spain. Pap. Reg. Sci. 2012, 91, 241-256. [CrossRef]

43. Greunz, L. Geographically and technologically mediated knowledge spillovers between European regions. Ann. Reg. Sci. 2003, 37, 657-680. [CrossRef]

44. Boschma, R.; Minondo, A.; Navarro, M. The emergence of new industries at the regional level in Spain: A proximity approximity approach based on product relatedness. Econ. Geogr. 2015, 89, 29-51. [CrossRef]

45. Cainelli, G.; Ganau, R.; Iacobucci, D. Do geographic concentration and vertically related variety foster firm productivity? Micro evidence from Italy. Growth Chang. 2016, 47, 197-217. [CrossRef]

46. Hartog, M.; Boschma, R.; Sotarauta, M. The impact of related variety on regional employment growth in Finland1993-2006: High-tech versus medium/low-tech. Ind. Innov. 2012, 19, 459-476. [CrossRef]

47. Virkanen, J. Effect of urbanization on metal deposition in the Bay of Töölönlahti, Southern Finland. Mar. Pollut. Bull. 1998, 36, 729-738. [CrossRef]

48. Leeuw, F.A.A.M.D.; Moussiopoulos, N.; Sahm, P.; Bartonova, A. Urban air quality in larger conurbations in the European Union. Environ. Model. Softw. 2001, 16, 399-414. [CrossRef]

49. Verhoef, E.T.; Nijkamp, P. Externalities in Urban Sustainability: Environmental Versus Localization-Type Agglomeration Externalities in a General Spatial Equilibrium Model of a Single-Sector Monocentric Industrial City. Ecol. Econ. 2002, 40,157-179. [CrossRef]

50. Duc, T.A.; Vachaud, G.; Bonnet, M.P.; Prieur, N.; Loi, V.D. Experimental investigation and modelling approach of the impact of urban wastewater on a tropical river; a case study of the Nhue River, Hanoi, Viet Nam. J. Hydrol. 2007, 334, 347-358. [CrossRef]

51. Cheng, $Z$. The spatial correlation and interaction between manufacturing agglomeration and environmental pollution. Ecol. Indic. 2016, 61, 1024-1032. [CrossRef]

52. Zeng, D.Z.; Zhao, L. Pollution havens and industrial agglomeration. J. Environ. Econ. Manag. 2009, 58, 141-153. [CrossRef]

53. Ehrenfeld, J. Putting a Spotlight on Metaphors and Analogies in Industrial Ecology. J. Ind. Ecol. 2010, 7, 1-4. [CrossRef]

54. Wagner, U.J.; Timmins, C.D. Agglomeration Effects in Foreign Direct Investment and the Pollution Haven Hypothesis. Environ. Resour. Econ. 2009, 43, 231-256. [CrossRef]

55. Yao, J.; Zan, X.H.; Li, Z. Analysis on the influence of industrial agglomeration on smog pollution based on spatial perspective. Agro Food Ind. Hi-Tech 2017, 28, 2876-2878.

56. Effiong, E.L. On the urbanization-pollution nexus in Africa: A semiparametric analysis. Qual. Quant. 2018, 52, 1-12. [CrossRef]

57. Zhang, K.; Dou, J. Agglomeration and pollution: Empirical analysis based on the 287 cities of China. J. Financ. Res. 2015, 12, 32-45.

58. He, C.; Huang, Z.; Ye, X. Spatial heterogeneity of economic development and industrial pollution in urban China. Stoch. Environ. Res. Risk Assess. 2014, 28,767-781. [CrossRef]

59. Copeland, B.R.; Taylor, M.S. North-South Trade and the Environment. Q. J. Econ. 1994, 109, $755-787$. Available online: http:/ / www.jstor.org/stable/2118421 (accessed on 10 January 2018). [CrossRef]

60. Jirčíková, E.; Pavelková, D.; Bialicdavendra, M.; Homolka, L. The age of clusters and its influence on their activity preferences. Technol. Econ. Dev. Econ. 2013, 19, 621-637. [CrossRef]

61. Ingstrup, M.B.; Damgaard, T. Cluster Facilitation from a Cluster Life Cycle Perspective. Eur. Plan. Stud. 2013, 21, 556-574. [CrossRef]

62. Wang, B.; Nie, X. Industrial Agglomeration and Environmental Governance: The Power or Resistance-Evidence from a Quasi-natural Experiment of Establishment of the Development Zone. Chin. Ind. Econ. 2016, 12, 75-89.

63. Chen, T. FDI, Technology Spillovers and Technology Gap. J. Financ. Res. 2003, 8, 59-69.

64. Hansen, B. Threshold Effects in Non-dynamic Panels: Estimation, Testing and Inference. J. Econom. 1999, 2, 345-368. [CrossRef]

65. Menzel, M.P.; Fornahl, D. Cluster life cycles-Dimensions and rationales of cluster evolution. Ind. Corp. Chang. 2009, 19, 205-238. [CrossRef]

66. Au, C.C.; Henderson, J.V. Are Chinese Cities Too Small? Rev. Econ. Stud. 2010, 73, 549-576. Available online: http:/ / www.jstor.org/stable/20185020 (accessed on 10 January 2018). [CrossRef] 
67. Qin, B.; Wu, J.F. Does urban concentration mitigate CO2 emissions? Evidence from China 1998-2008. China Econ. Rev. 2015, 35, 220-231. [CrossRef]

68. $\mathrm{Xu}, \mathrm{B}$; $\mathrm{Lin}, \mathrm{B} . \mathrm{Q}$. How industrialization and urbanization process impacts on $\mathrm{CO}_{2}$ emissions in China: Evidence from nonparametric additive regression models. Energy Econ. 2015, 48, 188-202. [CrossRef]

69. He, J.; Wang, H. Economic structure, development policy and environmental quality: An empirical analysis of environmental Kuznets curve with Chinese municipal data. Ecol. Econ. 2012, 76, 49-59. [CrossRef]

70. Henderson, V. The Urbanization Process and Economic Growth: The So-What Question. J. Econ. Growth 2003, 8, 47-71. Available online: https://search.proquest.com/docview/197700297?accountid=11524 (accessed on 10 January 2018).

71. Baomin, D.; Jiong, G.; Xin, Z. FDI and environmental regulation: Pollution haven or a race to the top? J. Regul. Econ. 2012, 41, 216-237. [CrossRef]

72. Pessoa, A. Agglomeration and regional growth policy externalities versus comparative advantages. Ann. Reg. Sci. 2014, 53, 1-27. [CrossRef]

73. Galliano, D.; Magrini, M.B.; Triboulet, P. Marshall's versus Jacobs' externalities in firm innovation performance: The case of French industry. Reg. Stud. 2015, 49, 1840-1858. [CrossRef]

74. Berliant, M.; Kun, P.S.; Ping, W. Taxing Pollution: Agglomeration and Walfare Consequences. Econ. Theory 2013, 10, 199-212. Available online: http:/ / www.jstor.org/stable/43562948 (accessed on 9 January 2018). [CrossRef]

75. Costantini, V.; Mazzanti, M.; Montini, A. Environmental Performance, Innovation and Spillovers. Evidence from a Regional NAMEA. Ecol. Econ. 2013, 89, 101-114. [CrossRef]

76. Jie, H. Pollution haven hypothesis and environmental impacts of foreign direct investment: The case of industrial emission of sulfur dioxide $\left(\mathrm{SO}_{2}\right)$ in Chinese provinces. Ecol. Econ. 2006, 60, 228-245. [CrossRef]

77. Han, F.; Xie, R.; Lu, Y.; Fang, J.; Liu, Y. The effects of urban agglomeration economies on carbon emissions: Evidence from Chinese cities. J. Clean. Prod. 2018, 172, 1096-1110. [CrossRef]

78. Peng, C.; Song, M.; Han, F. Urban economic structure, technological externalities, and intensive land use in China. J. Clean. Prod. 2017, 152, 47-62. [CrossRef]

79. $\mathrm{Xu}, \mathrm{B}$; $\mathrm{Lin}, \mathrm{B} . \mathrm{Q}$. Factors affecting carbon dioxide $\left(\mathrm{CO}_{2}\right)$ emissions in China's transport sector: A dynamic nonparametric additive regression model. J. Clean. Prod. 2015, 101, 311-322. [CrossRef]

80. Khazzoom, J.D. Economic Implications of Mandated Efficiency in Standards for Household Appliances. Energy J. 1980, 1, 21-40. Available online: http:/ / www.jstor.org/stable/41321476 (accessed on 9 January 2018).

81. Lin, B.Q.; Zhao, H.L. Technological progress and energy rebound effect in China's textile industry: Evidence and policy implications. Renew. Sustain. Energy Rev. 2016, 60, 173-181. [CrossRef]

82. Ozawa, T.; Phelps, N.A. Contrasts in agglomeration: Proto-industrial, industrial and post-industrial forms compared. Prog. Hum. Geogr. 2003, 27, 583-604. [CrossRef]

83. Martin, R.; Sunley, P. Path dependence and regional economic evolution. J. Econ. Geogr. 2006, 6, $395-437$. [CrossRef]

84. Wu, F.; Fan, L.W.; Zhou, P.; Zhou, D.Q. Industrial energy efficiency with $\mathrm{CO}_{2}$, emissions in China: A nonparametric analysis. Energy Policy 2012, 49, 164-172. [CrossRef]

85. Wang, D.T.; Chen, W.Y. Foreign direct investment, institutional development, and environmental externalities: Evidence from China. J. Environ. Manag. 2014, 135, 81-90. [CrossRef] [PubMed]

86. Pazienza, P. The Environmental Impact of the FDI Inflow in the Transport Sector of OECD Countries and Policy Implications. Int. Adv. Econ. Res. 2015, 21, 105-116. [CrossRef]

87. Feng, Z.; Chen, W. Environmental Regulation, Green Innovation, and Industrial Green Development: An Empirical Analysis Based on the Spatial Durbin Model. Sustainability 2018, 10, 223. [CrossRef]

88. Fan, R.G.; Luo, M. The Analysis of the Spatio-temporal Heterogeneity and the Impact of Rebound Effect in the Evolution of Energy Efficiency in China. Econ. Manag. J. 2014, 36, 1-12.

(C) 2018 by the authors. Licensee MDPI, Basel, Switzerland. This article is an open access article distributed under the terms and conditions of the Creative Commons Attribution (CC BY) license (http:/ / creativecommons.org/licenses/by/4.0/). 